\title{
Epo Is Relevant Neither for Microvascular Formation Nor for the New Formation and Maintenance of Mice Skeletal Muscle Fibres in Both Normoxia and Hypoxia
}

\author{
Luciana Hagström, ${ }^{1}$ Onnik Agbulut, ${ }^{2}$ Raja El-Hasnaoui-Saadani, ${ }^{1}$ Dominique Marchant, ${ }^{1}$ \\ Fabrice Favret, ${ }^{1}$ Jean-Paul Richalet, ${ }^{1}$ Michèle Beaudry, ${ }^{1}$ and Thierry Launay ${ }^{1,3}$ \\ ${ }^{1}$ Laboratoire "Réponses Cellulaires et Fonctionnelles à l'hypoxie", Université Paris 13, EA 2363, 97017 Bobigny, France \\ ${ }^{2}$ Laboratoire Stress et Pathologies du Cytosquelette, Unité de Biologie Adaptative et Fonctionnelle, Université Paris Diderot-Paris 7 \\ CNRS, 75013 Paris, France \\ ${ }^{3}$ Université Paris-Descartes, 75015 Paris, France
}

Correspondence should be addressed to Thierry Launay, thy.launay@free.fr

Received 30 October 2009; Revised 28 January 2010; Accepted 9 February 2010

Academic Editor: Aikaterini Kontrogianni-Konstantopoulos

Copyright (C) 2010 Luciana Hagström et al. This is an open access article distributed under the Creative Commons Attribution License, which permits unrestricted use, distribution, and reproduction in any medium, provided the original work is properly cited.

Erythropoietin (Epo) and vascular growth factor (VEGF) are known to be involved in the regulation of cellular activity when oxygen transport is reduced as in anaemia or hypoxic conditions. Because it has been suggested that Epo could play a role in skeletal muscle development, regeneration, and angiogenesis, we aimed to assess Epo deficiency in both normoxia and hypoxia by using an Epo-deficient transgenic mouse model (Epo-TAg $\left.{ }^{\mathrm{h}}\right)$. Histoimmunology, ELISA and real time RT-PCR did not show any muscle fiber atrophy or accumulation of active HIF- $1 \alpha$ but an improvement of microvessel network and an upregulation of VEGFR2 mRNA in Epo-deficient gastrocnemius compared with Wild-Type one. In hypoxia, both models exhibit an upregulation of VEGF120 and VEGFR2 mRNA but no accumulation of Epo protein. EpoR mRNA is not up-regulated in both Epo-deficient and hypoxic gastrocnemius. These results suggest that muscle deconditioning observed in patients suffering from renal failure is not due to Epo deficiency.

\section{Intro duction}

Erythropoietin (Epo) is know as a key-regulator of erythropoiesis stimulating proliferation, differentiation, and survival growth of erythroid precursor resulting in the increased production of red blood cells [1]. In both men and mice exposed to altitude, plasma Epo concentration reached a peak after a 24-hour period of exposure [2] and subsequently declining in a progressive manner within days or weeks $[3,4]$. It has been demonstrated the relative importance of altitude Epo-induced polycythemia in the process of acclimatisation to altitude hypoxia performed between days 4 and 9 of exposure [2].

Through specific binding to its receptor (EpoR), Epo triggers a chain of intracellular signaling events that depends on activation of Jak2 tyrosine kinase [5]. Studies dealing with the expression of EpoR revealed a role for Epo, in addition to erythropoiesis, on various tissues such as those of the central nervous system, pancreas, liver, lung, smooth, cardiac and skeletal muscles (for review see [6]). As a result, the effects of Epo as growth factor, antiapoptotic factor or angiogenic factor on these tissues are considered of a great interest.

Indeed, the EpoR has been identified in mouse $\mathrm{C} 2 \mathrm{C} 12$ primary myoblast cultures [7] as well as in human skeletal muscle [8]. On both $\mathrm{C} 2 \mathrm{C} 12$ cells and primary cultures of mouse myoblasts, Epo activates the proliferation of myogenic precursor cells [7]. More recently, the injection of recombinant human Epo (rHuEpo) has been shown to improve the regeneration process of rat soleus muscle [9]. Taken together, these results suggest a role for Epo on the development and regeneration of skeletal muscle. 
Epo was shown to have the same angiogenic power as vascular endothelial growth factor (VEGF) [10]. Kertesz et al. [11] demonstrated the role of Epo and VEGF in the formation of new blood vessels during the early development of tissues. Using Epo knock-out mutant, these authors showed that angiogenesis was defective while the vasculogenesis was relatively normal. On the other hand, Suzuki et al. [12] observed that the nonhematopoietic role of Epo is dispensable to organism development and angiogenesis under normal conditions. From those data, we suggest a compensatory mechanism to Epo deficiency in tissues. Then we may hypothesise that the default of oxygen transport to tissues leads to local hypoxia which induces the accumulation of Hypoxia-Inducible Factor- $1 \alpha$ (HIF- $1 \alpha$ ) and then the expression of the angiogenic factor VEGF as shown in anemic brain [13].

The VEGF-A (also referred as VEGF) protein comprises various isoforms of 121 to 206 amino acids in humans (120 to 205 in rodents), produced by alternative splicing during transcription [14, 15]. The 120, 164 and 188 isoforms are the most frequently expressed ones although each one has specific biological activities [16, 17]. VEGF121 is a freely diffusible protein whereas VEGF189 is almost completely sequestered in the extracellular matrix (ECM). VEGF165 has intermediate properties, as it is moderately diffusible but a significant fraction remains bound to the cell surface and ECM. Actually, the longer forms of VEGF are stably incorporated to the ECM but can be released in a diffusible form by several agents [18].

Epo deficiency is observed in patients suffering from severe renal failure inducing intense anaemia. Skeletal muscles of these patients present structural and functional abnormalities that contribute to explain, at least partly, their impaired exercise capacity, muscle deconditioning and decreased resistance to fatigue. There is a reduction in muscle mass associated with myofiber atrophy, mainly in type II fibers $[19,20]$. Moreover, reductions in muscle capillarity, as well as abnormalities of mitochondria are contributing factors for muscle fatigability [19-21]. Although muscle deconditioning in those patients could also be due to physical inactivity [20], those results suggest that Epo deficiency could have consequences on muscle structure and capillarisation.

In order to understand whether Epo is an important factor for muscle and capillary development and maintenance in hypoxia, we propose to use a model of erythropoietinSV40 $\mathrm{T}$ antigen (Epo-TAg ${ }^{\mathrm{h}}$ ) transgenic mice with a targeted disruption in the $5^{\prime}$ untranslated region of the Epo gene that dramatically reduces its expression $[22,23]$ and then induces severe anaemia. We aim to assess whether Epo deficiency alters skeletal muscle structure in either normoxia or hypoxia.

For this purpose, Epo-TAgh and wild-type (WT) mice were exposed to acute and chronic hypobaric hypoxia (equivalent to $4500 \mathrm{~m}$ ). Results were compared to those obtained in age-matched WT normoxic mice. We measured plasma and muscle Epo concentrations, active HIF- $1 \alpha$ and VEGF protein by Enzyme-linked immunosorbent assay (ELISA). To analyse the expression profile of each VEGF isoform, VEGFR1, VEGFR2 and EpoR mRNA, we used the real-time reverse transcriptase-polymerase chain reaction (RT-PCR). The expression of Epo mRNA was evaluated first by classical RT-PCR and second by real-time RTPCR. Moreover, the microvessel network was analysed in gastrocnemius muscles as described by Charifi et al. using the specific platelet endothelial cell adhesion molecule (PECAM) antibody directed against CD31. The capillary-to-fiber ratio $(C / F)$, the number of capillaries around a single fiber and the index of capillary tortuosity (LC/PF) were measured to evaluate the development of elongated vessels running parallel to the muscle fibers and the new sprouts from loops and cross connections [24].

\section{Materials and Methods}

2.1. Animal Model and Experimental Groups. For this study, male Wild-Type F1 BL6/CBA (Charles River, L'Arbresle, France) and male Epo deficient SV-40 T antigen (Epo-TAg ${ }^{\mathrm{h}}$ ) mice were divided randomly into six groups: (a) normoxic wild-type (Nx WT); (b) normoxic Epo-Tagh (Nx Epo$\mathrm{TAg}^{\mathrm{h}}$ ); (c) acute hypoxic wild-type (AHx WT); (d) acute hypoxic Epo-TAgh (AHx Epo-TAgh); (e) chronic hypoxic wild-type (CHx WT); and (f) chronic hypoxic Epo-TAgh (CHx Epo-TAgh $)$. At the moment of dissection all mice were 8 weeks old. The experimental procedures were performed in agreement with the Guide for the Care and Use of Laboratory Animals published by the National Institutes of Health (NIH Publication No. 85-23, Revised 1996) and were approved by the French "Ministère de l'Agriculture" Guidelines (authorisation number A-93-008-01).

Mice undergoing $\mathrm{AHx}$ and $\mathrm{CHx}$ were housed for 24 hours and 14 days, respectively, in a hypoxic chamber connected to a gas pump where air circulated at a pressure of $420 \mathrm{~mm} \mathrm{Hg}(\sim 4500 \mathrm{~m})$. Hypobaric hypoxia was maintained by a vacuum source at flow rates sufficient to prevent $\mathrm{CO}_{2}$ build-up. Chamber pressure was interrupted 20-30 minutes three times a week for cleaning, and food and water replacement. Pressure changes were achieved slowly and the renewal of air in the chamber was sufficient to ensure the composition of atmospheric air. Normoxic groups were kept in a normobaric normoxic environment $(760 \mathrm{~mm} \mathrm{Hg}$ ) outside the hypobaric chamber. All animals were housed in standard conditions (temperature $20-23^{\circ} \mathrm{C}$ with a 12 hours light: 12 hours dark cycle) and had free access to tap water and food.

At the end of time of each experiment, the mice were anaesthetized with pentobarbital, $60 \mathrm{mg} / \mathrm{Kg}$ intraperitoneally. Two intra cardiac blood samples were taken for hematocrit determination with a microcentrifuge (Microspin AMES, Germany) and hemoglobin measurement (OSM 3, Radiometer, Copenhagen, Denmark).

Under sterile conditions, gastrocnemius muscles were removed, rinsed in sterile phosphate buffered saline solution (PBS). The muscles were snap frozen in liquid nitrogen or mounted in tissue freezing embedding medium (Cryoblock, Labonord, France) for immunohistochemistry techniques and then immediately placed in liquid nitrogen cooled 
isopentane. Samples were stored at $-80^{\circ} \mathrm{C}$ until time of analysis. The mice were then killed with a lethal dose of pentobarbital.

2.2. Plasma and Muscle Epo Immunoassay. The quantitative determination of mouse Epo concentration in plasma and muscle extracts was assayed by Enzyme-Linked Immunosorbent assay (ELISA) by using the Quantikine Mouse Epo Immunoassay (R\&D systems Europe, Abingdon, UK). Plasma collection and assay procedure were carried out following the manufacturer's instructions. For determination of Epo plasma concentration, Nx WT, Nx Epo-TAgh , AHx WT and AHx Epo-TAgh were used ( $n=4$ in each group). The plasma was collected using heparin as an anticoagulant, centrifuged at $13,000 \times \mathrm{g}, 15$ minutes at $4^{\circ} \mathrm{C}$ and stored at $20^{\circ} \mathrm{C}$. Because nothing is known about Epo concentration in skeletal muscle, the gastrocnemius, soleus, plantaris, extensor digitorum longus and tibialis anterior muscles (hindlimb muscles) were mixed to ensure an adequate extraction volume and a sufficient protein quantity to ensure the detection by the kit. For this experiment all conditions were tested ( $n=5$ in each group). These five muscles were homogenized together in a very small volume of PBS $(1: 4$ weight/volume) to concentrate total proteins, centrifuged for 10 minutes, $5,000 \times \mathrm{g}$ at $4^{\circ} \mathrm{C}$ and directly stored at $-20^{\circ} \mathrm{C}$. After 2 freeze-thaw cycles to break-up the cell membranes, muscle homogenates were assayed without prior dilution whereas plasma samples required a 2 -fold dilution in a calibrator diluent provided in the kit. A standard curve was done in duplicate using a stock solution of Epo standard to produce a 2 -fold dilution series ranging from 3000 to $0 \mathrm{pg} / \mathrm{mL}$. In parallel, $50 \mu \mathrm{L}$ of sample were added to $50 \mu \mathrm{L}$ of assay diluent specific for mouse samples into each well of a microplate coated with a monoclonal antibody against mouse Epo and incubated for 2 hours on a microplate shaker at room temperature. A positive control consisting of a recombinant Epo solution, provided in the kit, was also loaded. After washing, $100 \mu \mathrm{L}$ of a monoclonal antibody against mouse Epo conjugated to horse radish peroxidase (HRP) were added to each well and incubated for 2 hours on a microplate shaker at room temperature. Finally, $100 \mu \mathrm{L}$ of substrate solution were added after 4 washes and incubated for 30 minutes at room temperature on the benchtop in the dark. After 30 minutes, the reaction was stopped using $100 \mu \mathrm{L}$ of a stop solution in each well. The optical density was measured at $450 \mathrm{~nm}$. The concentration of Epo $(\mathrm{pg} / \mathrm{mL})$ detected in each sample was compared to the Epo standard curve. Finally, data were expressed as the ratio of the quantity of Epo (in pg) to that of total protein (in $\mathrm{mg}$ ) for muscles.

2.3. Determination of Active HIF-1 $\alpha$. Nuclear extracts of gastrocnemius of Nx WT, Nx Epo-Tgh, AHx WT, AHx Epo-TAg ${ }^{\mathrm{h}}, \mathrm{CHx}$ WT and CHx Epo-TAg ${ }^{\mathrm{h}}$ mice $(n=5$ per group) were obtained by using lysis buffer A: $10 \mathrm{mM}$ HEPES (pH 7.9), $1.5 \mathrm{mM} \mathrm{MgCl} 2,10 \mathrm{mM} \mathrm{KCl}, 0.5 \mathrm{mM}$ DTT, $0.1 \% \mathrm{NP}-40,2 \mathrm{mM} \mathrm{Na} 3 \mathrm{VO} 4,5 \mathrm{mM} \mathrm{NaF}$, an antiproteinase coktail and lysis buffer B: $20 \mathrm{mM}$ HEPES (pH 7.9), $1.5 \mathrm{mM}$ $\mathrm{MgCl}_{2}, 420 \mathrm{mM} \mathrm{NaCl}, 0.5 \mathrm{mM}$ DTT, $25 \%$ glycerol, $2 \mathrm{mM}$
$\mathrm{Na} 3 \mathrm{VO} 4,5 \mathrm{mM} \mathrm{NaF}$ and antiprotease coktail as described in the protocol of DuoSet IC Mouse active HIF-1 $\alpha$ (R\&D System, Europe, Abingdon, UK). The determination of active HIF1- $\alpha$ has been carried out as described by the manufacturer (R\&D System, Europe, Abingdon, UK).

2.4. Total RNA Isolation and cDNA Synthesis. Total RNA was extracted from the gastrocnemius muscle of mice from different groups $(\mathrm{Nx}, \mathrm{AHx}$ and $\mathrm{CHx}$ from $\mathrm{WT}$ and EpoTAgh mice; $n=5$ in each group) by using the RNeasy Mini Kit and it was digested with RNase free DNase Set (Qiagen, Courtaboeuf, France) following the method provided by the manufacturer. RNA preparations were quantified by using an ultraviolet visible recording spectrophotometer (LKB Pharmacia Ultrospec) using absorbencies at 260 and $280 \mathrm{~nm}$. To evaluate the purity of the extracted RNA, absorbance ratios at $260 \mathrm{~nm} / 280 \mathrm{~nm}$ (RNA/protein) were determined. We controlled the 260/280 ratio which was between 1.8 and 1.9 , indicative of pure RNA. Reverse transcription (RT) was carried out to synthesize the first strand cDNA from $1.9 \mu \mathrm{g}$ of mRNA with the SuperScript III First-Strand Synthesys System (Invitrogen, Carlsbad, CA, USA).

2.5. Semiquantitative RT-PCR. Polymerase chain reaction (PCR) techniques were used to identify the expression of Epo mRNA in the experimental samples. The cDNA sequences for the genes of interest were obtained from GenBank. All the primers sequences and RT-PCR parameters used in this study are described in Table 1. The PCR reaction mix contained 10X reaction buffer, $50 \mathrm{mM} \mathrm{MgCl}_{2}$, dNTP mix $(10 \mathrm{mM}$ each dATP, dGTP, dCTP and dTTP at neutral $\mathrm{pH}$ ), $1 \mu \mathrm{M}$ primers of Epo or $\beta$-actin, Taq polymerase (Invitrogen, France), CDNA and sterile water. PCR was carried out by using a DNA Thermal Cycler (R\&D Sytem, England) as follows: $95^{\circ} \mathrm{C}$ for 5 minutes; then 35 cycles for $\beta$-actin and 38 for Epo of denaturation at $95^{\circ} \mathrm{C}$ for 1 minute, annealing at $60^{\circ} \mathrm{C}$ for 1 minute and extension at $72^{\circ} \mathrm{C}$ for 1 minute each. A $10 \mu \mathrm{L}$ portion of the amplified PCR product was analysed by electrophoresis on a $2 \%$ agarose gel that was stained with ethidium bromide for visualization of DNA bands by ultraviolet illumination. A 50-base pair (bp) ladder DNA molecular weight marker was used (Fermentas, France) to provide a size reference for the test reactions.

2.6. Real-Time RT-PCR. Real-time RT-PCR technique was used to identify the distribution of VEGF isoforms, VEGFR1 VEGFR2 and EpoR in the RNA samples. The cDNA sequences were obtained as described above and presented in Table 1. The VEGF common forward primer is located on exon 4, the VEGF120 reverse primer is located on the boundary of exon 5 and exon 7, VEGF164 reverse primer is located on the boundary of exon 5 and exon 8, and VEGF188 reverse primer is located on the boundary of exon 5 and exon 6.

The Light Cycler FastStart DNA Master SYBR Green I (Roche Biochemicals, Stockholm, Sweden) was used for quantitative analyses of the generated cDNA. The RT-PCR amplifications were performed in a total volume of $20 \mu \mathrm{L}$, 
TABLE 1: Sequence and hybridization temperature (Tm) of specific primers.

\begin{tabular}{lccccc}
\hline Gene name & Forward 5' to $3^{\prime}$ & Reverse 5' to $3^{\prime}$ & Tm & $\begin{array}{c}\text { Amplicon } \\
\text { size bps }\end{array}$ & $\begin{array}{c}\text { Genbank accession } \\
\text { number }\end{array}$ \\
\hline VEGF120 & GCCAGCACATAGAGAGAATGAGC & GGCTTGTCACATTTTTCTGG & $63^{\circ} \mathrm{C}$ & 94 & NM_001025257 \\
VEGF164 & GCCAGCACATAGAGAGAATGAGC & CAAGGCTCACAGTGATTTTCTGG & $63^{\circ} \mathrm{C}$ & 97 & M95200 \\
VEGF188 & GCCAGCACATAGAGAGAATGAGC & AACAAGGCTCACAGTGAACGCT & $63^{\circ} \mathrm{C}$ & 171 & NM_001025250 \\
VEGFR1 & CGAACTCCACCTCCATGTTT & TATCTTCATGGAGGCCTTGG & $60^{\circ} \mathrm{C}$ & 116 & NM_010228.3 \\
VEGFR2 & AGAGTTGGTGGAGCATTTGG & TAGGCAGGGAGAGTCCAGAA & $60^{\circ} \mathrm{C}$ & 125 & NM_010612.2 \\
Epo & AATGGAGGTGGAAGAACAGG & ACCCGAAGCAGTGAAGTGA & $60^{\circ} \mathrm{C}$ & 155 & NM_007942 \\
EpoR & GCTCCGGGATGGACTTCA & GAGCCTGGTGCAGGCTACAT & $60^{\circ} \mathrm{C}$ & 86 & NM_010149 \\
$\beta$-actin & AGAGGGAAATCGTGCGTGAC & CAATAGTGATGACCTGGCCGT & $62^{\circ} \mathrm{C}$ & 138 & NM_007393 \\
\hline
\end{tabular}

containing $5 \mu \mathrm{L}$ cDNA sample, $4 \mu \mathrm{L}$ LightCycler-FastStart DNA Master SYBR Green I, $0.5 \mu \mathrm{L}$ of each primer, and $2.5 \mathrm{mM} \mathrm{MgCl}$. For each reaction, the polymerase was activated by a preincubation at $95^{\circ} \mathrm{C}$ for 10 minutes. Amplification was then performed for 45 cycles of switching between $95^{\circ} \mathrm{C}$ for $10 \mathrm{~s}$, gene dependant $\mathrm{Tm}$ for 5 to $8 \mathrm{~s}$, and $72^{\circ} \mathrm{C}$ for 8 to $15 \mathrm{~s}$ depending on the length of the amplicon and followed by a melting point analysis from 65 to $95^{\circ} \mathrm{C}$. The results were represented as threshold cycle numbers ( $C_{t}$ values). Control cDNA of normoxic mouse lung was diluted and amplified to create standard curves by plotting $C_{t}$ values versus cDNA templates. Relative amounts of mRNA, normalised by $\beta$-actin were calculated from $C_{t}$ values according to the manufacturer's description.

2.6.1. Calculation of Relative Quantification Values. The relative quantification values were calculated according to the manufacturer's protocol (Roche Biochemicals, Stockholm, Sweden). The $C_{p}$ represents the PCR cycle at which an increase in fluorescence above a baseline signal can be detected. $C_{p}$ value was used to calculate the amount of RTPCR product compared with the internal control, $\beta$-actin. The $C_{p}$ value of $\beta$-actin was subtracted from the gene $C_{p}$ value to evaluate the mean change in $C_{p}$ in each experimental group.

2.7. Analysis of VEGFA Protein Concentration by ELISA. Gastrocnemius muscles from different groups (Nx, AHx and $\mathrm{CHx}$ from WT and Epo-TAgh mice; $n=4$ in each group) were weighted and homogenized in 5 -fold volume in ice cold buffer ( $10 \mathrm{mM}$ tris, $\mathrm{pH} 8)$. The suspension was centrifuged at $13,000 \mathrm{~g}$ at $4^{\circ} \mathrm{C}$ for 15 minutes. The protein content of the supernatant was determined by the Bradford assay using bovine serum albumin (BSA) as standard. The quantity of total VEGFA in the gastrocnemius muscles from WT and Epo-TAg ${ }^{\mathrm{h}}$ mice in normoxia and following acute and chronic hypoxic exposure was determined by a commercial highsensitivity ELISA kit (DuoSet Kit) according to the manufacturer's instructions (R\&D Systems Europe, Abingdon, UK). Measurements were done in duplicate.

\subsection{Immunohistochemistry}

2.8.1. Section Preparation. For visualization of vascular endothelial cells we used the monoclonal antibody CD31 which recognizes platelet endothelial cell adhesion molecule (PECAM-1), a glycoprotein strongly expressed in all endothelial cells. To that end, serial $10 \mu \mathrm{m}$ transverse sections from the midbelly region of frozen gastrocnemius muscles samples from Nx WT, Nx Epo-TAgh, CHx WT and CHx Epo-TAgh ( $n=5$ in each group) were cut in a cryostat (Leica, France) at $-20^{\circ} \mathrm{C}$ and mounted in microscope slides (Superfrost Plus, Fisher Scientific, France). The slides were fixed in cold acetone and incubated in 3\% hydrogen peroxidase $\left(\mathrm{H}_{2} \mathrm{O}_{2}\right)$ to inhibit any endogenous peroxidase. Then, they were blocked with 3\% BSA before incubating with rat antimouse CD31/PECAM-1 monoclonal antibody (BD Biosciences Pharmingen, France) diluted 1:100 in the protein blocking solution. Tissue sections were incubated with a biotynilated antirat secondary antibody (Dako, France) diluted 1:200 in blocking solution. Staining was carried out using streptavidin-HRP (Dako, France) and revelation was done by incubating slides in the dark in a 3, 3'-diaminobenzidine (DAB) solution (Sigma, France). Negative controls were obtained by omitting the primary or secondary antibody. The sections were counterstained with haematoxylin (Sigma, France) and mounted in aqueous mounting agent (Aquatex, Darmstadt, Germany).

Because the capillary tortuosity in muscles is a function of sarcomere length, the longitudinal $10 \mu \mathrm{m}$ cryo-sections were stained by using haematoxylin (Sigma, France) and eosin (Sigma, France) to make sure it was constant between the different conditions. The length occupied by 10 consecutive sarcomeres was measured per longitudinal section in 2 samples of $\mathrm{Nx}$ and $\mathrm{CHx}$ with the software described below.

This technique of immunostaining does not allow to identify the various types of blood vessels (arterioles, capillaries or venules) nor the diameter of them. Consequently we used "microvessel network" as a generic term.

2.8.2. Morphometry and Assessment of Microvessel Network. Stained sections were studied under a light microscope 
TABLE 2: Body weight, hematocrit and haemoglobin concentration in wild-type (WT) and Epo-Tagh mice in normoxia (Nx), acute hypoxia for 24 hours (AHx) and chronic hypoxia for 14 days ( $\mathrm{CHx})(n=14$ in each group).

\begin{tabular}{|c|c|c|c|c|c|c|}
\hline & \multicolumn{3}{|c|}{ WT } & \multicolumn{3}{|c|}{ Epo-TAg } \\
\hline & $\mathrm{Nx}$ & $\mathrm{AHx}$ & $\mathrm{CHx}$ & $\mathrm{Nx}$ & $\mathrm{AHx}$ & $\mathrm{CHx}$ \\
\hline Body weight (g) & $24.2 \pm 1.3$ & $23.1 \pm 1.1$ & $23.5 \pm 0.9$ & $23.0 \pm 1.1$ & $23.6 \pm 1.3$ & $23.1 \pm 1.9$ \\
\hline Muscle weight (g) & $0.15 \pm 0.03$ & $0.12 \pm 0.01$ & $0.15 \pm 0.03$ & $0.15 \pm 0.02$ & $0.12 \pm 0.02$ & $0.13 \pm 0.01$ \\
\hline Hematocrit (\%) & $45.3 \pm 1.6$ & $51.7 \pm 1.3^{*}$ & $60.3 \pm 1.6^{*} \#$ & $19.3 \pm 1.1 \$$ & $21.6 \pm 1.5^{*} \$$ & $27 \pm 1.9^{*} \$$ \\
\hline [Haemoglobin] g/dL & $17.3 \pm 0.3$ & $16.9 \pm 0.4$ & $19.2 \pm 0.5^{*}$ & $6.7 \pm 0.5 \$$ & $6.1 \pm 0.2 \$$ & $7.1 \pm 0.5 \$$ \\
\hline
\end{tabular}

Values are means \pm SD

${ }^{*}$ Significantly different from corresponding Nx group, $P<.05$; \#, significantly different from corresponding AHx group, $P<.01 ; \$$, significantly different from corresponding WT group, $P<.05$.

connected to a digital camera (Coolpix 990, Nikon). Photographs were taken at $\mathrm{x} 40$ magnification. Image calibration was done by taking a photo of a micrometric glass coverslip at X40 magnification. Explora Nova image analysing software (Explora Nova Morpho, La Rochelle, France) was used to analyse the images. To determine the microvessel network we analysed two different sections. On each section, we have chosen two different areas for the deep region and for the superficial region. Capillary density (CD) and capillary-tofiber ratio $(C / F)$ were quantified for each entire area. All transversely cut capillaries were counted and if a capillary was sectioned longitudinally, it was counted as one each time it crossed a junction between three or more muscle fibers. The individual fiber parameters were evaluated by counting an average of 70 fibers by area. For each individual fiber the following parameters were evaluated: (a) the number of capillaries around a single fiber (capillary contacts, CC); (b) the CC relative to the area of the fiber (CCFA); (c) the length of the contact between the microvessels and the fibers (LC); (d) the capillary-to-fiber ratio on an individual-fiber basis $\left(C / F_{i}\right)$; (e) fiber cross-sectional area $(\mathrm{FA})$; and (f) fiber perimeter (PF). Obliquity in fiber sectioning was assessed by using the form factor (FF) that represents: $(4 \pi \mathrm{x}$ fiber area) $/(\text { fiber perimeter) })^{2}$ (a perfect circle will have a FF of 1 , whereas a line's FF will approach zero). The capillary-to-fiber perimeter exchange (CFPE) index was calculated to obtain an index of the size of the capillary-to-fiber interface and was determined from the equation: CFPE index $=\left(C / F_{i}\right) / P[25]$.

The index of capillary tortuosity can be indirectly determined by LC/PF. This index is expressed as a percentage of muscle fiber perimeters in contact with the capillary wall.

All quantitative analyses were blinded by the same observer.

2.9. Statistical Analysis. Two-way analysis of variance (ANOVA; hypoxia versus Epo deficiency) was carried out and Newman-Keuls test was used for post hoc test. A nonparametric Mann-Whitney test was exceptionally used for plasma Epo measurements since the Nx WT group was only three mice making impossible to perform a twoway ANOVA. The statistical analyses were performed using Stastitica software (StartSoft, Tulsa, OK). All values are expressed as mean $\pm \mathrm{SD}$. Differences were considered to be significant at $P \leq .05$.

\section{Results}

3.1. Animal Characteristics. Body and muscle weights, hematocrits and haemoglobin concentrations of $\mathrm{Nx}, \mathrm{AHx}$ and CHx of WT and Epo-TAg mice are presented in Table 2. Body and muscle weights were similar in all groups whether submitted or not to hypoxia. Hematocrit and haemoglobin concentrations were significantly $57 \%$ and $61 \%$ lower in $\mathrm{Nx}$ Epo-TAgh mice than in Nx WT group demonstrating severe anaemia (global effect, $P<.001$ ). Exposure to hypoxia for 14 days induced a polycythemia in WT $(P<.05)$. Epo-TAgh mice also responded to hypoxia exposure, and hematocrit values were $40 \%$ higher in $\mathrm{CHx}$ than in $\mathrm{Nx}$ mice $(P<.05)$. However, haemoglobin concentration in Epo-TAg ${ }^{\text {h }}$ mice did not change when compared to normoxic values.

\subsection{Epo Is Not Expressed in Skeletal Muscle in both Normoxia} and Acute Hypoxia. In order to validate our model we first determined the amount of Epo. We chose to measure the plasma concentration in $\mathrm{Nx}$ and $\mathrm{AHx}$ conditions for 24 hours because the hypoxia-induced erythropoiesis activation occurred during the early phase of exposure (5-9 days) [2] with a peak of expression of Epo at 24 hours. The plasma and muscle Epo measurements showed a strong reduction in Epo-deficient mice (Epo-TAg ${ }^{\mathrm{h}}$ mice) (Table 3). In Nx Epo$\mathrm{TAg}^{\mathrm{h}}$ mice, Epo plasma concentration was $56 \%$ lower than in Nx WT group $(P<.05)$. Acute hypoxia exposure increased Epo plasma concentration in both groups, but remained 3fold lower than in AHx WT animals $(P<.05)$. Similar results were reported for Epo muscle concentration which was 2 -fold lower in Nx Epo-TAgh mice than in Nx WT group $(P<.05)$. Acute and chronic hypoxia exposure did not change Epo concentration in the skeletal muscle in neither WT nor Epo-TAg ${ }^{\mathrm{h}}$ mice. Those results raise the question of the secretion of Epo within the skeletal muscle. Our results of classical RT-PCR did not demonstrate any expression of mRNA encoding Epo whatever the experimental condition (Figure 1(a)). Those results were confirmed by real-time RTPCR (data not shown).

3.3. mRNA Encoding EpoR is Not Upregulated in Epo-Deficient Skeletal Muscles. Using the same transgenic model [13] we demonstrated an upregulation of mRNA encoding the EpoR in the brain which suggests an optimization of Epo signalling 
TABle 3: Plasma and muscle Epo concentration in wild-type (WT) and Epo-TAg mice in normoxia (Nx), after acute hypoxia for 24 hours (AHx) and chronic hypoxia for 14 days $(\mathrm{CHx})(n=4$ or 5 in each group).

\begin{tabular}{lccccc}
\hline & \multicolumn{2}{c}{ Plasma $[$ Epo] pg/mL } & \multicolumn{3}{c}{ Muscle [Epo] pg/mg of total protein } \\
& $\mathrm{Nx}$ & $\mathrm{AHx}$ & $\mathrm{Nx}$ & $\mathrm{AHx}$ & $\mathrm{CHx}$ \\
\hline WT & $122 \pm 16$ & $460 \pm 39^{*}$ & $0.121 \pm 0.03$ & $0.097 \pm 0.02$ & $0.128 \pm 0.06$ \\
Epo-TAgh & $53 \pm 18 \$$ & $162 \pm 25^{*} \$$ & $0.060 \pm 0.04 \$$ & $0.082 \pm 0.02$ & $0.101 \pm 0.07$ \\
\hline
\end{tabular}

Values are means \pm SD.

* significantly different from corresponding Nx group, $P<.05$; $\$$, significantly different from corresponding WT group, $P<.05$.

TABLE 4: Indices of the microvascular supply and morphological data of gastrocnemius muscle fibers in normoxia (Nx), and after exposure to chronic hypoxia for 14 days $(\mathrm{CHx})$ ( $n=5$ in each group).

\begin{tabular}{|c|c|c|c|c|c|c|c|c|}
\hline & \multicolumn{4}{|c|}{$\mathrm{Nx}$} & \multicolumn{4}{|c|}{$\mathrm{CHx}$} \\
\hline & \multicolumn{2}{|c|}{ Superficial region } & \multicolumn{2}{|c|}{ Deep region } & \multicolumn{2}{|c|}{ Superficial region } & \multicolumn{2}{|c|}{ Deep region } \\
\hline & WT & Epo-TAg ${ }^{\mathrm{h}}$ & WT & Epo-TAg ${ }^{\mathrm{h}}$ & WT & Epo-TAg ${ }^{\mathrm{h}}$ & WT & Epo-TAg ${ }^{\mathrm{h}}$ \\
\hline \multicolumn{9}{|c|}{ Global microvessel indices } \\
\hline $\mathrm{CD}\left(\mathrm{cap} / \mathrm{mm}^{2}\right)$ & $546 \pm 174$ & $611 \pm 95$ & $1699 \pm 350$ & $1587 \pm 180$ & $601 \pm 105$ & $624 \pm 81$ & $1845 \pm 393$ & $1701 \pm 211$ \\
\hline$C / F$ & $1.33 \pm 0.16$ & $1.70 \pm 0.17^{*}$ & $2.23 \pm 0.29$ & $2.69 \pm 0.29^{*}$ & $1.27 \pm 0.15$ & $1.65 \pm 0.26^{*}$ & $2.28 \pm 0.20$ & $2.62 \pm 0.29^{*}$ \\
\hline \multicolumn{9}{|c|}{ Individual fiber microvessels indices } \\
\hline $\mathrm{CC}$ & $2.89 \pm 0.63$ & $3.57 \pm 0.56^{*}$ & $5.20 \pm 0.78$ & $6.27 \pm 0.54^{*}$ & $2.95 \pm 0.16$ & $3.54 \pm 0.46^{*}$ & $5.22 \pm 0.82$ & $6.19 \pm 0.41^{*}$ \\
\hline$C / F_{i}$ & $1.05 \pm 0.11$ & $1.37 \pm 0.21^{*}$ & $2.16 \pm 0.26$ & $2.46 \pm 0.35^{*}$ & $1.09 \pm 0.13$ & $1.34 \pm 0.20^{*}$ & $2.15 \pm 0.19$ & $2.58 \pm 0.21^{*}$ \\
\hline $\mathrm{LC} / \mathrm{PF}(\%)$ & $8.96 \pm 1.26$ & $11.9 \pm 0.93^{*}$ & $30.2 \pm 7.3$ & $35.4 \pm 8.7$ & $10.2 \pm 1.84$ & $12.56 \pm 0.82^{*}$ & $32.5 \pm 8.0$ & $37.0 \pm 3.90$ \\
\hline \multicolumn{9}{|c|}{ Morphological data of muscle fibers } \\
\hline $\mathrm{FA}\left(\mu \mathrm{m}^{2}\right)$ & $2521 \pm 286$ & $2411 \pm 188$ & $1259 \pm 158$ & $1494 \pm 165$ & $2189 \pm 314$ & $2499 \pm 204$ & $1232 \pm 246$ & $1361 \pm 133$ \\
\hline $\mathrm{PF}(\mu \mathrm{m})$ & $215 \pm 17$ & $222 \pm 21$ & $160 \pm 16$ & $173 \pm 14$ & $198 \pm 13$ & $220 \pm 7$ & $153 \pm 18$ & $165 \pm 11$ \\
\hline Form factor & $0.63 \pm 0.02$ & $0.63 \pm 0.03$ & $0.64 \pm 0.06$ & $0.64 \pm 0.03$ & $0.62 \pm 0.02$ & $0.63 \pm 0.02$ & $0.65 \pm 0.04$ & $0.65 \pm 0.04$ \\
\hline
\end{tabular}

Values are means $\pm \mathrm{SD}$;

Main effect of Epo deficiency: significantly different from WT group: ${ }^{*} P<.05$.

$\mathrm{CD}$ : capillary density; $C / F$ : capillary-to-fiber ratio; CC: number of capillaries around single fibers; $C / F_{i}$ : individual capillary-to-fiber ratio; LC/PF: length of the contact between microvessels and the fiber/perimeter of the fibers; FA: fiber area; PF: perimeter.

to Epo deficiency. In the skeletal muscle we did not find any upregulation of EpoR mRNA (Figure 1(b)). Moreover, it can be noticed that the amount of EpoR is extremely weak when compared to $\beta$-actin (Figure 1(b)).

\subsection{Epo Deficient Gastrocnemius Does Not Exhibit Fiber} Atrophy and it Presents Developed Microvessel Network. We hypothesised that Epo deficiency could induce changes in the microvessel network of the skeletal muscle as well as muscle fiber atrophy. Immunostaining analysis of CD 31/PECAM1 was designed to visualise the distribution of vessels in gastrocnemius muscles (superficial and deep region) of WT and Epo-TAgh mice after exposure to chronic hypoxia (Figure 2). The morphometric parameters measured are reported in Table 4. The two-way ANOVA showed a main global effect of Epo deficiency in the microvessel network when expressed in $C / F, C / F_{i}$ and CC. These three parameters were higher in Epo-TAgh mice when compared to WT $(P<$ .05 ; Table 4) in both superficial and deep regions of the gastrocnemius muscle (Figure 2).

The LC/PF ratio was higher in Epo-deficient mice compared with WT mice, but only in the superficial region of gastrocnemius $\left(+34 \%\right.$ and $+23 \%$ in Nx Epo-TAg ${ }^{\mathrm{h}}$ and $\mathrm{CHx}$ Epo-TAgh groups, resp.; main global effect of Epo deficiency, $P<.05)$. No statistical difference was shown in the deep regions, but the values of Epo-TAgh mice tended to be higher than WT mice in normoxia and after chronic hypoxia (Table 4). The absence of any change in FF showed that the cross-sectional morphology of muscle fibers remained unchanged (Table 4). Taken together, the results of FF and $\mathrm{LC} / \mathrm{PF}$ suggest a change in microvessel tortuosity in the superficial region of the gastrocnemius muscle in Epo-TAgh mice.

The CD, FA and PF were not significantly altered in any examined groups and experimental conditions (Table 4). Equality, the CC expressed in relation to fiber area (CCFA) and the $C / F_{i}$ ratio expressed in relation to fiber perimeter (CFPE) were similar in all groups, whether submitted to hypoxia or not (data not shown).

3.4.1. Sarcomere Length. The sarcomere length of the gastrocnemius was homogeneous among myofibrils of each group (data not shown). 


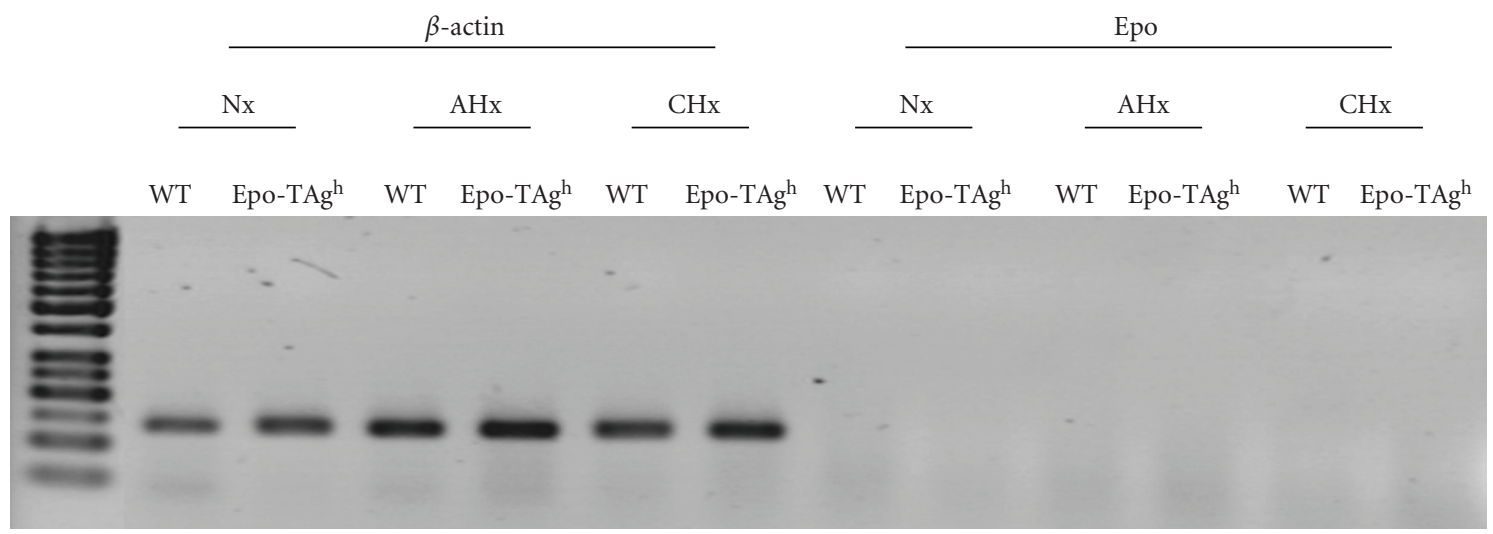

(a)



(b)

FIgURE 1: Expression of Epo and EpoR mRNA in gastrocnemius muscle of wild-type (WT) and Epo-TAg mice in normoxia (Nx) and following acute hypoxia for 24 hours (AHx) and chronic hypoxia for 14 days (CHx). (a) Semi-quantitative RT-PCR of Epo mRNA compare to $\beta$-actin. (b) Quantitative determination of EpoR mRNA in all experimental conditions. Values are means \pm SD.

3.5. Local Hypoxia Is Not Observed in Adult Epo-Deficient Gastrocnemius. Because Epo is required for oxygen delivery we suggested that Epo deficiency could induce local hypoxia. Then the amount of HIF- $1 \alpha$ was evaluated in normoxia as well as in hypoxia. The amount of active HIF- $1 \alpha$ was not changed between WT and Epo-TAgh mice in both normoxia and hypoxia (Figure 3(a)). mRNA encoding HIF$1 \alpha$ is unchanged in $\mathrm{Nx}$ Epo-TAg ${ }^{\mathrm{h}}$ mice compared to $\mathrm{Nx}$ WT one (Figure 3(b)). When exposed to acute hypoxia both groups exhibit an upregulation of HIF- $1 \alpha$ mRNA $(P<.001$; Figure 3(b)) while no difference was observed in the $\mathrm{CHx}$ groups.

3.6. VEGF Protein Is Not Over-Expressed in Epo-Deficient Gastrocnemius Muscle. We analysed the amount of VEGF protein in gastrocnemius muscle of WT and Epo-TAg ${ }^{\mathrm{h}}$ mice both in normoxia and submitted to acute and chronic hypoxia by ELISA. The VEGF protein concentrations are presented in Figure 3(c).

No significant difference was observed in VEGF protein level between WT and Epo-TAgh normoxic groups. In WT mice, the level of VEGF protein increased by $29 \%(P<.01)$ after acute exposure to hypoxia. In contrast, VEGF protein content was reduced by $21 \%$ after $\mathrm{CHx}$, in comparison with normoxic values $(P<.05)$. The VEGF protein content in Epo-TAgh mice failed to change with hypoxia exposure.

In comparison with AHx WT, the amount of VEGF protein was 30\% lower in AHx Epo-TAg ${ }^{\mathrm{h}}(P<.01)$ whereas it was 28\% higher in CHx Epo-TAgh than in CHx WT $(P<.01)$.

3.7. Differential Regulation of mRNA VEGF120, 164 and 188 Isoforms and VEGFR1 and 2 mRNA. Using real-time RT-PCR, we quantified the expression of mRNA spliced variant isoforms VEGF120, VEGF164 and VEGF188 as well as VEGFR1 and VEGFR2 of WT and Epo-Tagh in the gastrocnemius muscle of $\mathrm{Nx}, \mathrm{AHx}$ and $\mathrm{CHx}$ mice groups in order to examine the responses of VEGF isoforms to Epo deficiency and decreased oxygen transfer. Our results showed that the expression of VEGF120 and VEGFR2 were modulated in hypoxia and/or Epo deficiency only (Figures 4(a) and 4(e)). VEGF 120 mRNA was up regulated $(P<$ .001) in acute hypoxia in WT mice compared to Nx groups. For Epo-deficient mice, significant upregulation of VEGF120 


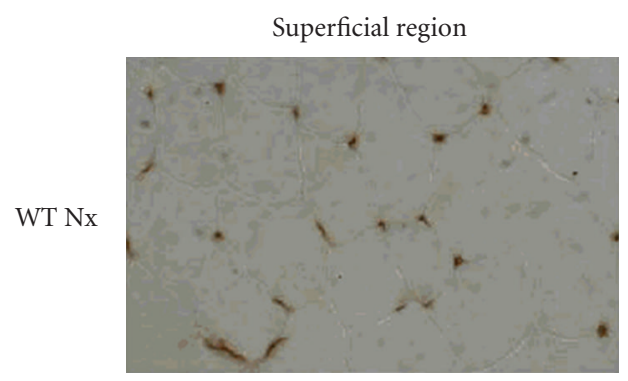

(a)

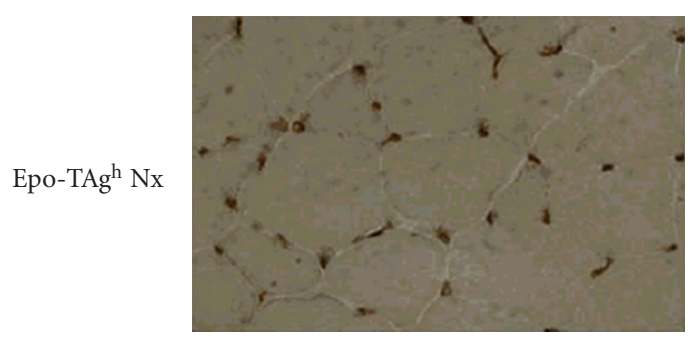

(b)

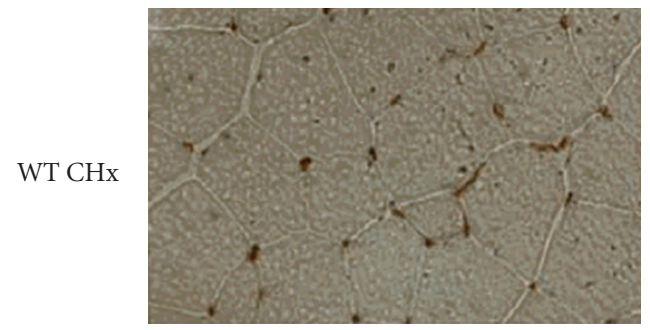

(c)

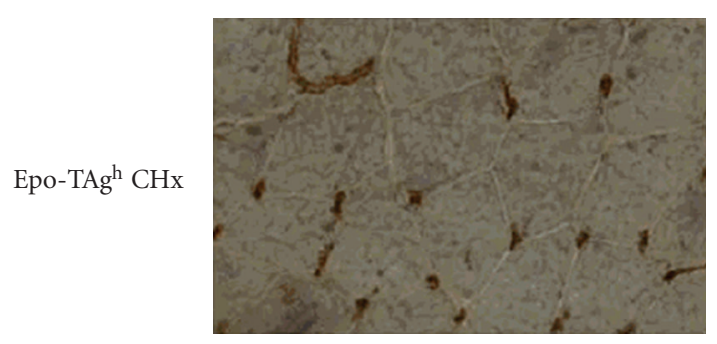

(d)

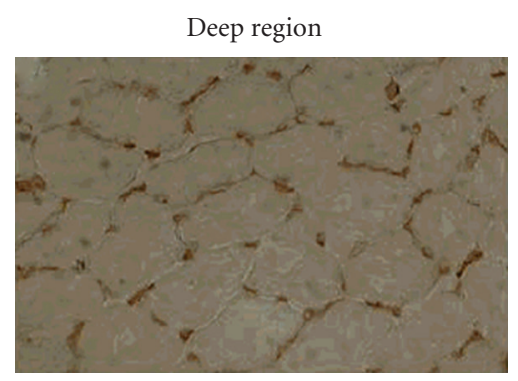

(e)

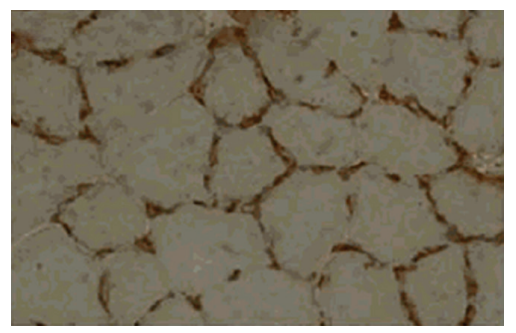

(f)



(g)

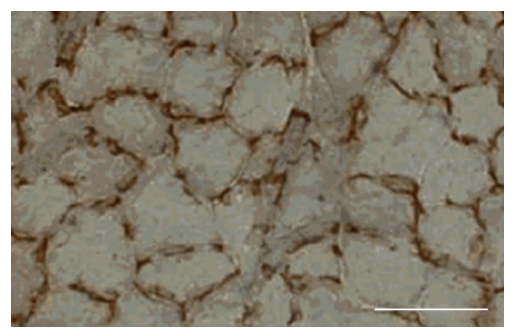

(h)

FIgURE 2: Muscle cross-section of the superficial ((a) to (d)) and deep region ((e) to (h)) of the gastrocnemius muscle of wild-type (WT) and Epo-TAg ${ }^{\mathrm{h}}$ mice stained by using the monoclonal antibody antiCD31 for the detection of the microvesssel network in normoxia (Nx) and following chronic hypoxia for 14 days $(\mathrm{CHx})$. Epo deficiency develops the microvessel network in mice. Bars $=50 \mu \mathrm{m}$.

mRNA was observed in CHx only $(P<.001)$. VEGFR2 mRNA was upregulated in Nx Epo-TAgh group compared to Nx WT $(P<.001)$. In chronic hypoxia, VEGFR2 mRNA were upregulated in both Epo and WT groups compared to corresponding normoxic ones (Figure 4(e)).

The rate of expression of VEGF164 and VEGF188 mRNA remained unaffected by either hypoxia exposure or Epo deficiency (Figures 4(b) and 4(c)). VEGFR1 mRNA was upregulated by acute hypoxia in Epo-Tagh mice compared to Nx Epo-TAg ${ }^{\mathrm{h}}$ and AHx WT $(P<.01$; Figure 4(d)). No difference was observed in chronic hypoxia and/or in normoxic Epo-deficient mice compared to WT ones.

\section{Discussion}

In this work, we aimed to determine whether Epo deficiency could be involved in the skeletal muscle fibers atrophy and the alteration of microvessel network. In fact, it has been suggested that Epo could be an important growth factor for skeletal muscle development and repair. Our principal findings are: (1) Epo-deficient anemic muscles do not exhibit atrophy in both normoxia and hypoxia; (2) microvessel network of Epo-deficient mice is improved compared to WT mice; (3) when exposed to hypoxia Epo is not accumulated in hindlimb muscles and both mice linages exhibit an 




(a)



(b)

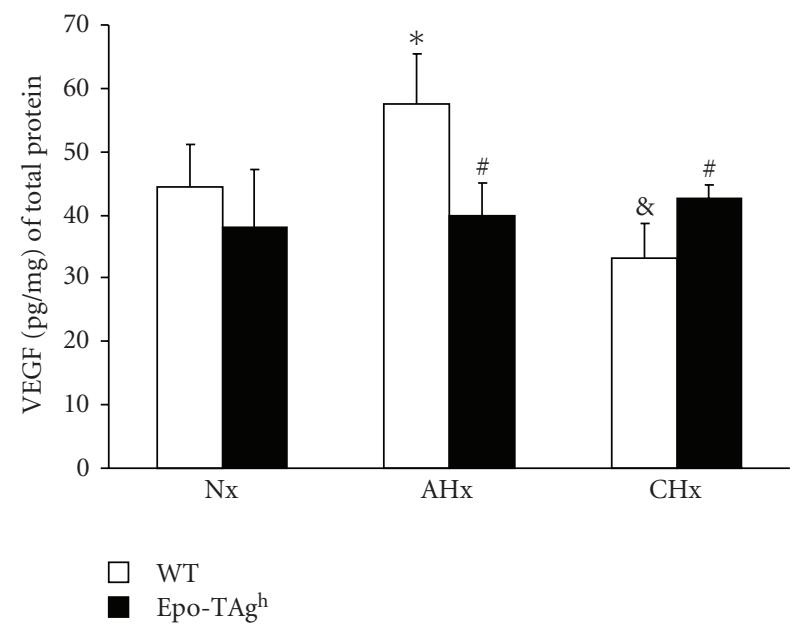

(c)

FIGURE 3: Quantitative determination of (a) activated HIF- $\alpha$ protein and (b) HIF- $\alpha$ mRNA and (c) VEGF protein in the gastrocnemius muscle of wild-type (WT) and Epo-TAgh mice in normoxia (Nx) and following acute hypoxia for 24 hours (AHx) and chronic hypoxia for 14 days $(\mathrm{CHx})$. Values are means $\pm \mathrm{SD} .{ }^{*}$, significantly different from corresponding $\mathrm{Nx}$ group, $P<.01$. \#, significantly different from corresponding WT group, $P<.05$. \&, significantly different from corresponding AHx group. \#, $P<.05$.

upregulation of VEGF120 and VEGFR2 in gastrocnemius muscle; (4) EpoR expression is not upregulated by either hypoxia or Epo deficiency.

Our transgenic model (Epo-TAgh ${ }^{\mathrm{h}}$ ) is able to survive to 14 days in severe hypoxia $(4500 \mathrm{~m})$ despite the weak expression of Epo. In fact, in these mice, the expression of Epo gene is reduced, but the production of Epo still exists [23]. The amount of Epo is dramatically reduced in plasma resulting in a severe anaemia in these mice while a slight reduction is observed in hindlimb muscles. However, although Epo availability was lower in Epo-TAg ${ }^{\mathrm{h}}$ than in WT mice after acute exposure to hypoxia ( 24 hours), the Epo protein expression remained responsive to the hypoxic stimulus as previously described [23]. Actually, in mice submitted to acute hypoxia, plasma Epo is increased in both WT and Epo-TAg ${ }^{\text {h }}$ compared to normoxic mice even if the Epo level is considerably lower in Epo-TAgh than in WT mice. In hindlimb muscles, we did not find any difference between Epo levels in normoxic and acute hypoxic mice. In rodent, it has been demonstrated an upregulation of mRNA encoding Epo in kidney as early as the first hour of exposure to hypoxia leading to a peak of plasma Epo between the 12th and the 24 th $\mathrm{h}$ of exposure [26]. Similar results were obtained in the brain [13]. Since we did not detect the presence of RNA encoding Epo at any experimental point, the weak amount of Epo protein we measured in muscle probably corresponded to the Epo present in capillaries or in the interstitial environment of myofibers. Those results do not support the idea that Epo is secreted by the skeletal muscle when exposed to both normoxia or hypoxia at rest as it has been shown in rats submitted to exercise [27]. Furthermore, the low amount of EpoR encoding mRNA as well as the absence of regulation of its expression in Epo-deficient or hypoxic gastrocnemius consolidates the hypothesis by which Epo is not an important growth factor in the skeletal muscle in our experimental conditions. In order to explain the presence of mRNA encoding EpoR in the gastrocnemius muscle we suggest that few nonmuscle cells could express EpoR. Lately, LeBaron et al. [28] demonstrated that cells dispersed in the fascia of rat quadriceps were able to respond to Epo injections by STAT5 phosporylation. Taken together these results suggest that circulating nonresident cells originating 


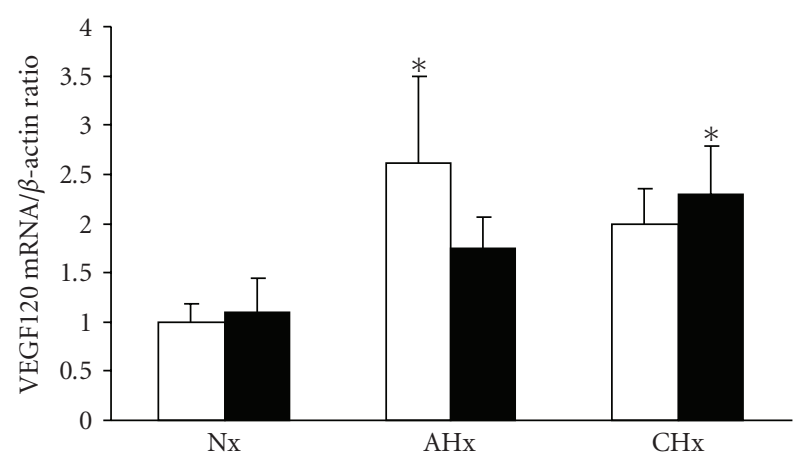

(a)



(c)

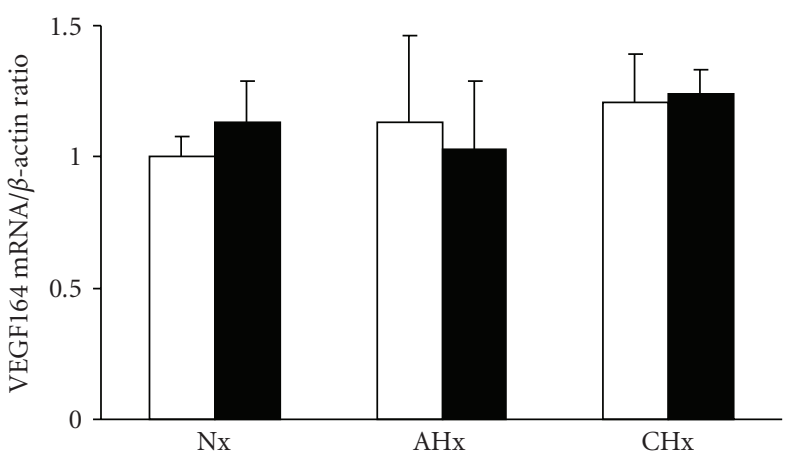

(b)



(d)



$\square$ WT

- Epo-TAgh

(e)

FIGURE 4: Quantitative determination of VEGF and VEGFR isoforms mRNA in the gastrocnemius muscle of wild-type (WT) and Epo-TAg ${ }^{\text {h }}$ mice in normoxia $(\mathrm{Nx})$ and following acute hypoxia for 24 hours (AHx) and chronic hypoxia for 14 days (CHx). (a) VEGF120 mRNA. (b) VEGF164 mRNA. (c) VEGF188 mRNA. (d) VEGFR1 mRNA. (e) VEGFR2 mRNA. Values are means \pm SD. *, significantly different from corresponding Nx group, $P<.01$. \#, significantly different from corresponding WT group, $P<.01$. \&, significantly different from corresponding $\mathrm{CHx}$ group, $P<.05$.

from bone marrow could explain the expression of EpoR. Moreover, the injection of rHuEpo in musculocutaneous tissues induces the upregulation of endothelial nitric oxide synthase (eNOS) and prevents musculocutaneous tissues from ischemic damage [29]. These results suggest that Epo could have some undirect effects on the skeletal muscle such as increasing the perfusion of arteriolar or the mobilisation of nonresident stem cells in traumatizing conditions. In our work, we did not test these hypotheses.
In the present study, Epo deficiency does not induce skeletal muscle atrophy even when mice are exposed to hypoxia, but we observe the improvement of microvessel network when determined through parameters evaluating angiogenesis such as $C / F, C / F_{i}$, CC and LC/PF. The capillary number per area of muscle $(\mathrm{CD})$ is an unreliable index of angiogenesis if the muscle fibers enlarge or atrophy [30, 31]. Indeed, some studies showed that body and muscle mass is reduced after exposure to hypoxia. These changes 
induce a decrease in muscle fiber size and an increase in $\mathrm{CD}$ not necessarily by the formation of new capillaries [32]. In our work, we did not find a loss of body mass or muscle and the FA was not decreased in Epo-deficient mice. The great variations of surface area measures can explain the nonsignificant change in $\mathrm{CD}$ despite the increase of $C / F$. Therefore, we may conclude that the improvement of microvessel network can be attributed to angiogenesis in both studied regions. The improvement of both $C / F$ and tortuosity $(\mathrm{LC} / \mathrm{PF})$ in the superficial region is probably due to the fact that glycolytic fibers, which are predominant in this region, are more sensitive to local hypoxia [33].

Epo and VEGF are important growth factors involved in angiogenesis [10]. Indeed, in vitro, these factors were shown to stimulate endothelial cell migration and proliferation, which are key steps in the formation of new vessels $[10,34]$. Our data are consistent with conclusions of Suzuki et al. [12] suggesting that the lack of Epo induces a default of oxygen supply to tissues which in turn activates a locally HIF-VEGF dependent angiogenic pathway. Although we did not demonstrate any accumulation of either active HIF- $1 \alpha$ or VEGF protein, we suggest that the improvement of capillary network occurred during muscle development. These results show that Epo is dispensable first for microvessel formation and maintenance in the skeletal muscle.

In chronic altitude hypoxia, several biological responses occur to compensate for the negative effects of reduced oxygen availability [35]. Nevertheless, there has been a number of discrepancies in the literature about physiological adaptations to altitude and angiogenesis in the skeletal muscle (for review, see [36, 37]). Hansen-Smith et al. [38] found an increased capillary density in the white part of the gastrocnemius muscle but no change in the number of capillaries around a single fiber in the red and white parts of gastrocnemius of mice submitted to 7 and 21 days of hypoxia $(\sim 7200 \mathrm{~m})$. Smith and Marshall [39] showed that an arteriolar remodelling within the skeletal muscle in rats during acclimatisation to chronic hypoxia occurs between the 7 th and the 18th day of exposure to hypoxia $(4500 \mathrm{~m})$. Conversely, Snyder et al. [40] and Olfert et al. [41] did not find any hypoxia-induced angiogenesis in murin models. Deveci et al. [42] suggested that the angiogenic response might be divergent between oxidative and glycolytic rat muscles. For that reason we chose a regionalised muscle for our experiments: the gastrocnemius. The deep region of this muscle is characterized as predominantly fast-twitch red fibers and the superficial region as predominantly fasttwitch white fibers [43]. Our results confirm the idea that chronic hypoxia does not provide a sufficient stimulus to induce capillary growth in mice skeletal muscles at least in the early phase of acclimatisation of hypoxia. Actually, it has been described by some authors as a late acclimatisation (up to 5 weeks) to hypoxia which consists in skeletal muscle atrophy [44] inducing in some cases the increase of capillary density (for review [32]). The real cause of this atrophy is not yet well known and factors such as intestinal malabsorption or inactivity have been suggested to be involved in this late acclimatisation to hypoxia. In this work we focused on the role of Epo on the Epo-dependent early phase of acclimatisation, so we may conclude that the lack of change in muscle capillary bed and the absence of skeletal muscle fiber atrophy in response to ambient hypoxia is not affected by Epo deficiency.

All studies dealing with hypoxia, VEGF and skeletal muscles have addressed the VEGF164, which is the major isoform of VEGF in the skeletal muscle [41]. We did not find any changes in VEGF164 and VEGF188 expression in both Epo-deficient or hypoxic gastrocnemius muscles. Interestingly, both Epo-deficient and WT mice exhibit a VEGF120 response to hypoxia. This response is combined with the upregulation of VEGFR2 in WT mice. Among all VEGF isoforms, VEGF120 has been shown to have the weakest angiogenic effect. VEGF120/120 mutants exhibit severe defects in vessel network $[16,45]$. Moreover, it has been demonstrated that VEGF120 does not induce either the activation or the accumulation of endothelial cells in culture. Lately, it has been proposed that VEGF120, when binding to VEGFR2 receptor, may be involved in the control of dilatation and permeability of vessels [46] especially on endothelial cells of the human umbilical cord. Moreover, it has been demonstrated that VEGF120 in brain melanoma was able to diffuse away from the tumour in order to recruit vasculature from surrounding tissues [47]. Taken together, these results may suggest that acute hypoxia induces the upregulation of VEGF120 which acts through VEGFR2 signalling and improves the recruitment of existing capillaries in order to ameliorate oxygen supply to the muscle. Surprisingly, the upregulation of VEGF120 in Epo-deficient gastrocnemius is delayed when compared to WT. This phenomenon needs further investigation in order to understand if this delay is due to (1) Epo deficiency; (2) upregulation of VEGFR1, which is known to regulate the action of VEGFR2, or (3) the fact that VEGFR2 is already over-expressed in Epo-deficient mice. Furthermore, these results suggest a nonangiogenic adaptation of microvessels when both groups of mice were exposed to hypoxia but this hypothesis needs to be verified through further investigation, using new imaging techniques, for instance.

To conclude, this report showed that the gastrocnemius muscle possesses the remarkable feat to compensate Epo deficiency-induced anaemia by developing its microvessel network. Therefore Epo deficiency alone is not a sufficient factor to explain muscle deconditioning in patients suffering from severe renal failure. Moreover, we showed that the skeletal muscle exhibits an upregulation of VEGF120 and VEGFR2 when submitted to hypoxia, which suggests an improvement in the dilatation of pre-existing microvessel network in order to ameliorate oxygen supply.

\section{Acknowledgment}

The authors gratefully acknowledge Stephane Chambris for his technical support. 


\section{References}

[1] F. Li, Z. Z. Chong, and K. Maiese, "Erythropoietin on a tightrope: balancing neuronal and vascular protection between intrinsic and extrinsic pathways," Neurosignals, vol. 13, no. 6, pp. 265-289, 2004.

[2] C. E. Bozzini, et al., "Enhanced erythropoietin production during hypobaric hypoxia in mice under treatments to keep the erythrocyte mass from rising: implications for the adaptive role of polycythemia," High Altitude Medicine and Biology, vol. 6, no. 3, pp. 238-246, 2005.

[3] P. H. Abbrecht and J. K. Littell, "Erythrocyte life-span in mice acclimatized to different degrees of hypoxia," Journal of Applied Physiology, vol. 32, no. 4, pp. 443-445, 1972.

[4] J. P. Richalet, J. C. Souberbielle, A. M. Antezana, et al., "Control of erythropoiesis in humans during prolonged exposure to the altitude of 6,542 m," American Journal of Physiology, vol. 266, no. 3, part 2, pp. R756-R764, 1994.

[5] B. A. Witthuhn, F. W. Quelle, O. Silvennoinen, et al., "JAK2 associates with the erythropoietin receptor and is tyrosine phosphorylated and activated following stimulation with erythropoietin," Cell, vol. 74, no. 2, pp. 227-236, 1993.

[6] W. Jelkmann, "Erythropoietin after a century of research: younger than ever," European Journal of Haematology, vol. 78, no. 3, pp. 183-205, 2007.

[7] M. Ogilvie, X. Yu, V. Nicolas-Metral, et al., "Erythropoietin stimulates proliferation and interferes with differentiation of myoblasts," Journal of Biological Chemistry, vol. 275, no. 50, pp. 39754-39761, 2000.

[8] C. Lundby, Y. Hellsten, M. B. F. Jensen, A. S. Munch, and H. Pilegaard, "Erythropoietin receptor in human skeletal muscle and the effects of acute and long-term injections with recombinant human erythropoietin on the skeletal muscle," Journal of Applied Physiology, vol. 104, no. 4, pp. 1154-1160, 2008.

[9] R. Rotter, M. Menshykova, T. Winkler, et al., "Erythropoietin improves functional and histological recovery of traumatized skeletal muscle tissue," Journal of Orthopaedic Research, vol. 26, no. 12, pp. 1618-1626, 2008.

[10] K. Jaquet, K. Krause, M. Tawakol-Khodai, S. Geidel, and K.H. Kuck, "Erythropoietin and VEGF exhibit equal angiogenic potential," Microvascular Research, vol. 64, no. 2, pp. 326-333, 2002.

[11] N. Kertesz, J. Wu, T. H.-P. Chen, H. M. Sucov, and H. $\mathrm{Wu}$, "The role of erythropoietin in regulating angiogenesis," Developmental Biology, vol. 276, no. 1, pp. 101-110, 2004.

[12] N. Suzuki, O. Ohneda, S. Takahashi, et al., "Erythroid-specific expression of the erythropoietin receptor rescued its null mutant mice from lethality," Blood, vol. 100, no. 7, pp. 22792288, 2002.

[13] R. El Hasnaoui-Saadani, A. Pichon, D. Marchant, et al., "Cerebral adaptations to chronic anemia in a model of erythropoietin-deficient mice exposed to hypoxia," American Journal of Physiology, vol. 296, no. 3, pp. R801-R811, 2009.

[14] Z. Poltorak, T. Cohen, R. Sivan, et al., "VEGF145, a secreted vascular endothelial growth factor isoform that binds to extracellular matrix," Journal of Biological Chemistry, vol. 272, no. 11, pp. 7151-7158, 1997.

[15] E. Tischer, R. Mitchell, T. Hartman, et al., "The human gene for vascular endothelial growth factor: Multiple protein forms are encoded through alternative exon splicing," Journal of Biological Chemistry, vol. 266, no. 18, pp. 11947-11954, 1991.
[16] Y.-S. Ng, R. Rohan, M. E. Sunday, D. E. Demello, and P. A. D'Amore, "Differential expression of VEGF isoforms in mouse during development and in the adult," Developmental Dynamics, vol. 220, no. 2, pp. 112-121, 2001.

[17] C. J. Robinson and S. E. Stringer, "The splice variants of vascular endothelial growth factor (VEGF) and their receptors," Journal of Cell Science, vol. 114, no. 5, pp. 853-865, 2001.

[18] J. E. Park, G.-A. Keller, and N. Ferrara, "The vascular endothelial growth factor (VEGF) isoforms: differential deposition into the subepithelial extracellular matrix and bioactivity of extracellular matrix-bound VEGF," Molecular Biology of the Cell, vol. 4, no. 12, pp. 1317-1326, 1993.

[19] I. H. Fahal, G. M. Bell, J. M. Bone, and R. H. T. Edwards, "Physiological abnormalities of skeletal muscle in dialysis patients," Nephrology Dialysis Transplantation, vol. 12, no. 1, pp. 119-127, 1997.

[20] J. D. Kopple, T. Storer, and R. Casburi, "Impaired exercise capacity and exercise training in maintenance hemodialysis patients," Journal of Renal Nutrition, vol. 15, no. 1, pp. 44-48, 2005.

[21] E. Kouidi, M. Albani, K. Natsis, et al., "The effects of exercise training on muscle atrophy in haemodialysis patients," Nephrology Dialysis Transplantation, vol. 13, no. 3, pp. 685699, 1998.

[22] K. Binley, Z. Askham, S. Iqball, et al., "Long-term reversal of chronic anemia using a hypoxia-regulated erythropoietin gene therapy," Blood, vol. 100, no. 7, pp. 2406-2413, 2002.

[23] P. H. Maxwell, M. K. Osmond, C. W. Pugh, et al., "Identification of the renal erythropoietin-producing cells using transgenic mice," Kidney International, vol. 44, no. 5, pp. 1149-1162, 1993.

[24] N. Charifi, F. Kadi, L. Féasson, F. Costes, A. Geyssant, and C. Denis, "Enhancement of microvessel tortuosity in the vastus lateralis muscle of old men in response to endurance training," Journal of Physiology, vol. 554, no. 2, pp. 559-569, 2004.

[25] R. T. Hepple, "A new measurement of tissue capillarity: the capillary-to-fibre perimeter exchange index," Canadian Journal of Applied Physiology, vol. 22, no. 1, pp. 11-22, 1997.

[26] W. Jelkmann, "Erythropoietin,” Journal of Endocrinological Investigation, vol. 26, no. 9, pp. 832-837, 2003.

[27] H. Ameln, T. Gustafsson, C. J. Sundberg, et al., "Physiological activation of hypoxia inducible factor-1 in human skeletal muscle," FASEB Journal, vol. 19, no. 8, pp. 1009-1011, 2005.

[28] M. J. LeBaron, T. J. Ahonen, M. T. Nevalainen, and H. Rui, "In vivo response-based identification of direct hormone target cell populations using high-density tissue arrays," Endocrinology, vol. 148, no. 3, pp. 989-1008, 2007.

[29] F. Rezaeian, R. Wettstein, J.-F. Egger, et al., "Erythropoietininduced upregulation of endothelial nitric oxide synthase but not vascular endothelial growth factor prevents musculocutaneous tissue from ischemic damage," Laboratory Investigation, vol. 90, no. 1, pp. 40-51, 2010.

[30] O. Birot and A. X. Bigard, "Réponses du réseau capillaire du muscle squelettique à l'entraînement]," Science and Sports, vol. 18, no. 1, pp. 1-10, 2003.

[31] B. M. Prior, P. G. Lloyd, H. T. Yang, and R. L. Terjung, "Exercise-induced vascular remodeling," Exercise and Sport Sciences Reviews, vol. 31, no. 1, pp. 26-33, 2003.

[32] H. Hoppeler and M. Vogt, "Muscle tissue adaptations to hypoxia," The Journal of Experimental Biology, vol. 204, part 18, pp. 3133-3139, 2001. 
[33] O. J. Birot, et al., "Exercise-induced expression of vascular endothelial growth factor mRNA in rat skeletal muscle is dependent on fibre type," The Journal of Physiology, vol. 552, part 1, pp. 213-221, 2003.

[34] A. Anagnostou, E. S. Lee, N. Kessimian, R. Levinson, and M. Steiner, "Erythropoietin has a mitogenic and positive chemotactic effect on endothelial cells," Proceedings of the National Academy of Sciences of the United States of America, vol. 87, no. 15, pp. 5978-5982, 1990.

[35] J. P. Richalet and J. P. Herry, Médecine de L'alpinisme et des Sports de Montagne, Masson, Paris, France, 4th edition, 2006.

[36] E. Breen, K. Tang, M. Olfert, A. Knapp, and P. Wagner, "Skeletal muscle capillarity during hypoxia: VEGF and its activation," High Altitude Medicine and Biology, vol. 9, no. 2, pp. 158-166, 2008.

[37] O. Mathieu-Costello, "Muscle adaptation to altitude: tissue capillarity and capacity for aerobic metabolism," High Altitude Medicine and Biology, vol. 2, no. 3, pp. 413-425, 2001.

[38] F. M. Hansen-Smith, L. H. Blackwell, and G. R. Joswiak, "Expression of muscle capillary alkaline phosphatase is affected by hypoxia," Journal of Applied Physiology, vol. 73, no. 2, pp. 776-780, 1992.

[39] K. Smith and J. M. Marshall, "Physiological adjustments and arteriolar remodelling within skeletal muscle during acclimation to chronic hypoxia in the rat," Journal of Physiology, vol. 521, no. 1, pp. 261-272, 1999.

[40] G. K. Snyder, E. E. Wilcox, and E. W. Burnham, "Effects of hypoxia on muscle capillarity in rats," Respiration Physiology, vol. 62, no. 1, pp. 135-140, 1985.

[41] I. M. Olfert, E. C. Breen, O. Mathieu-Costello, and P. D. Wagner, "Chronic hypoxia attenuates resting and exerciseinduced VEGF, flt-1, and flk-1 mRNA levels in skeletal muscle," Journal of Applied Physiology, vol. 90, no. 4, pp. 1532$1538,2001$.

[42] D. Deveci, J. M. Marshall, and S. Egginton, "Relationship between capillary angiogenesis, fiber type, and fiber size in chronic systemic hypoxia," American Journal of Physiology, vol. 281, no. 1, pp. H241-H252, 2001.

[43] R. B. Armstrong and R. O. Phelps, "Muscle fiber type composition of the rat hindlimb," American Journal of Anatomy, vol. 171, no. 3, pp. 259-272, 1984.

[44] J. D. Luedeke, R. D. McCall, R. M. Dillaman, and S. T. Kinsey, "Properties of slow- and fast-twitch skeletal muscle from mice with an inherited capacity for hypoxic exercise," Comparative Biochemistry and Physiology-Part A, vol. 138, no. 3, pp. 373382, 2004.

[45] V. Mattot, L. Moons, F. Lupu, et al., "Loss of the VEGF164 and VEGF188 isoforms impairs postnatal glomerular angiogenesis and renal arteriogenesis in mice," Journal of the American Society of Nephrology, vol. 13, no. 6, pp. 1548-1560, 2002.

[46] Y. Zhang, M. Furumura, and E. Morita, "Distinct signaling pathways confer different vascular responses to VEGF 121 and VEGF 165," Growth Factors, vol. 26, no. 3, pp. 125-131, 2008.

[47] B. Kusters, R. M. W. De Waal, P. Wesseling, et al., "Differential effects of vascular endothelial growth factor A isoforms in a mouse brain metastasis model of human melanoma," Cancer Research, vol. 63, no. 17, pp. 5408-5413, 2003. 

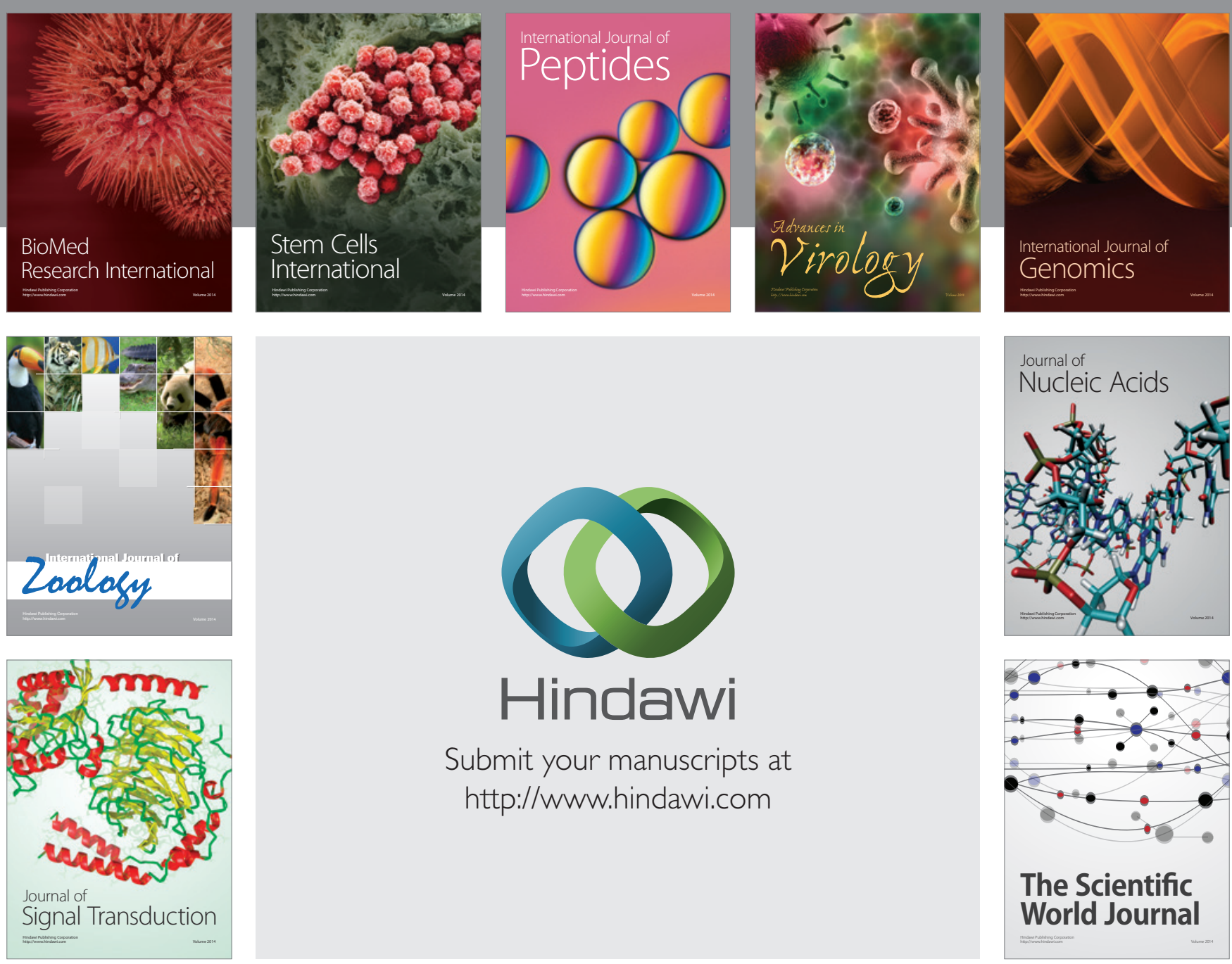

Submit your manuscripts at

http://www.hindawi.com
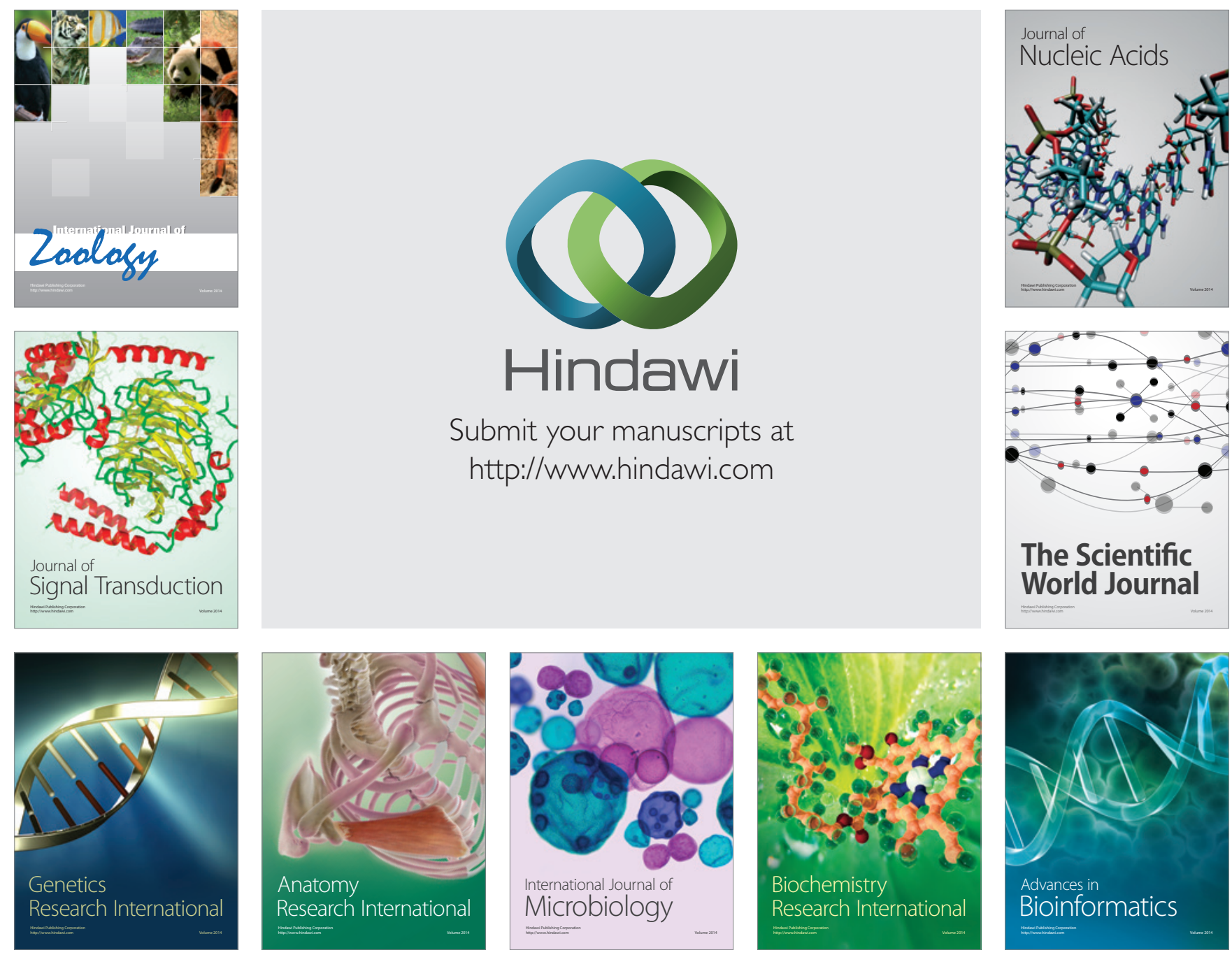

The Scientific World Journal
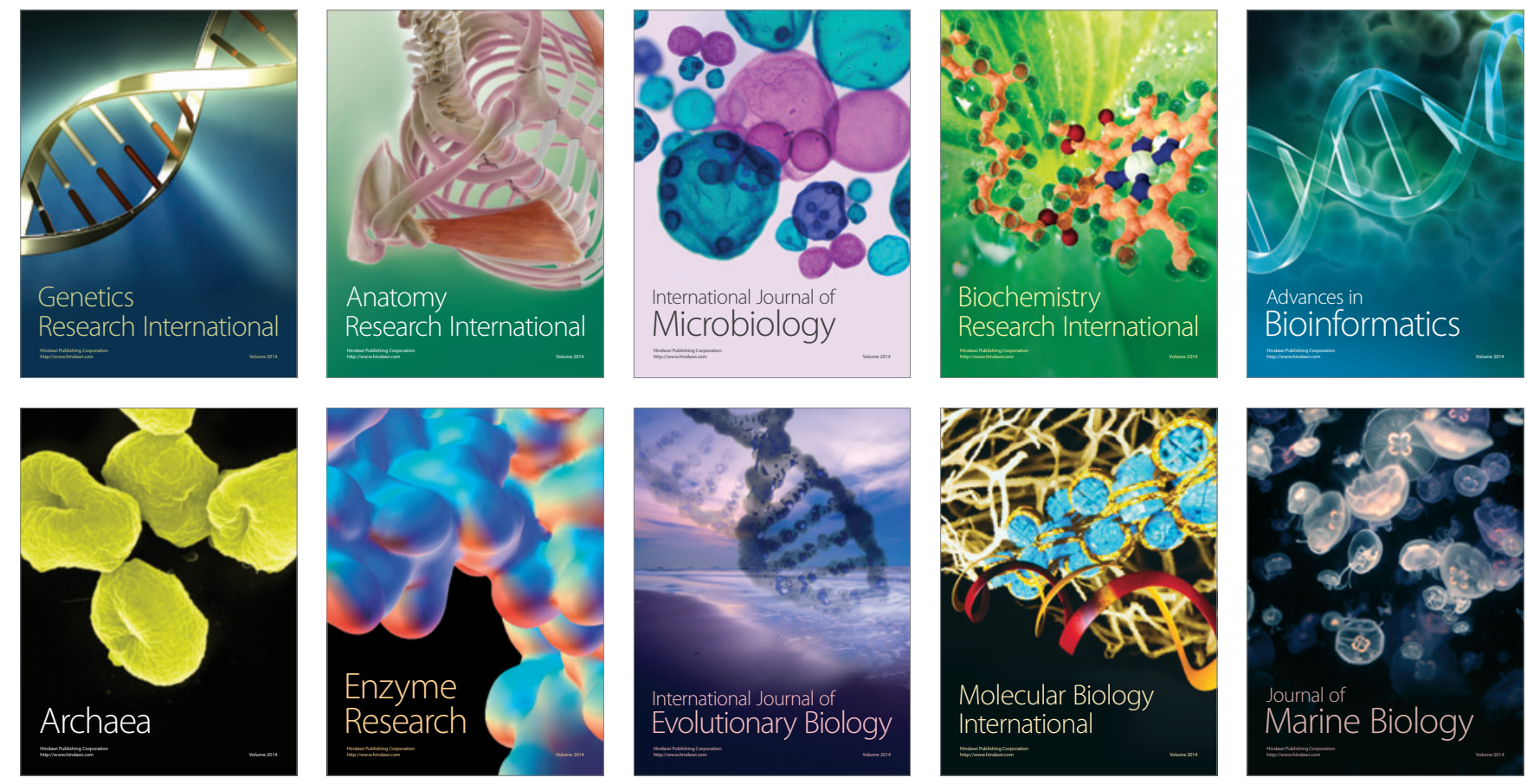